\title{
A review of pain pumps in plastic surgery
}

\author{
Geethan J Chandran MD, Donald H Lalonde MD FRCS
}

GJ Chandran, DH Lalonde. A review of pain pumps in plastic surgery. Can J Plast Surg 2010;18(1):15-18.

Continuous infusions of local anesthetics for postoperative analgesia have been used for several years by numerous surgical subspecialties. Plastic surgery has only recently embraced these pain pumps, most of which have been used in breast and abdominal surgery. Many different pain pump systems are available. They have been used in many studies and have been found to be effective in improving postoperative analgesia, decreasing narcotic use, and decreasing nausea and vomiting. They have little associated morbidity and systemic toxicity. However, the efficacy of these pain pumps in various areas of plastic surgery need to be studied in well-designed prospective clinical trials. The present paper reviews the current status of the available evidence, usefulness and limitations of the use of pain pumps in plastic surgery.

Key Words: Analgesia; Continuous infusion; Pain pump; Postoperative pain

$\mathrm{D}$ ifferent methods of postsurgical anesthesia have been extensively investigated in the surgical and anesthesia literature. Traditionally, postoperative pain has been managed with narcotics, nonsteroidal anti-inflammatories and muscle relaxants. However, surveys of patients reveal that $30 \%$ to $86 \%$ report moderate to severe postoperative pain (1). This leads to patient discomfort, poor satisfaction and unintended or prolonged hospital admissions. Furthermore, these commonly used medications have significant side effects including nausea, vomiting, pruritis, urinary retention, constipation, sedation, gastrointestinal bleeding and even death. Other modalities, including epidural and continuous peripheral nerve blockade, are also used for postoperative pain control and have been shown to decrease opioid use; these may also decrease postoperative nausea and vomiting (PONV). Unfortunately, these can be expensive and can have potentially high failure rates $-5 \%$ to $25 \%$ (1). Using continuous infusions of local anesthetics, pain pumps have effectively decreased postoperative pain, PONV and opioid use $(2-4)$.

\section{LOCAL ANESTHETICS}

Local anesthetics have been used intraoperatively for analgesia in the immediate postoperative period. Commonly, amide local anesthetics have been used. These block pain from nociceptive afferent neurons in the wound by blocking the threshold of excitation of the neuron. Recently, there has been increasing evidence that these local anesthetics may reduce pain through other mechanisms (2). Local anesthetics may inhibit local inflammatory response to injury by decreasing inflammatory cytokine release from neutrophils, decreasing neutrophil adhesion to endothelium, decreasing edema and decreasing oxygen free radical formation (1). Bupivacaine, the most commonly

\section{Le point sur les pompes analgésiques en chirurgie esthétique}

\begin{abstract}
On utilise les perfusions continues d'anesthésiques locaux pour l'analgésie postopératoire depuis de nombreuses années dans plusieurs spécialités chirurgicales. La chirurgie esthétique l'a adoptée seulement il y a peu de temps, et dans la plupart des cas, pour les chirurgies mammaires et abdominales. Il existe plusieurs systèmes de pompes analgésiques différents. Ils ont été utilisés dans de nombreuses études et se sont révélés efficaces pour améliorer l'analgésie postopératoire, réduire le recours aux narcotiques et atténuer les nausées et les vomissements. Ces systèmes sont associés à une morbidité et une toxicité systémique faibles. Toutefois, leur efficacité dans différents domaines de la chirurgie esthétique mérite de faire l'objet d'essais cliniques prospectifs rigoureusement conçus. Le présent article passe en revue l'état actuel des preuves disponibles sur l'utilité et les limites des pompes analgésiques en chirurgie plastique.
\end{abstract}

used agent in pain pumps, is an amide local anesthetic with a half-life of $3.5 \mathrm{~h}$ and, if combined with adrenaline, the half-life can be extended to $5 \mathrm{~h}$ to $7 \mathrm{~h}(1,2)$.

\section{PAIN PUMP KITS}

Pain pumps using continuous infusions of local anesthetic agents have been studied in various types of surgical procedures $(1,5-18)$. They are placed in the surgical site and local anesthetics are delivered to the site. Typically, $0.25 \%$ bupivacaine is the agent used and can be infused continuously, bolused or delivered via a patient-controlled delivery system. The $0.25 \%$ bupivacaine is usually infused at $2 \mathrm{~mL} / \mathrm{h}$ for $48 \mathrm{~h}$, delivering $120 \mathrm{mg}$ per day. This is well below the recommended maximum dose of $400 \mathrm{mg}$ in $24 \mathrm{~h}(1,2)$.

Varying doses and duration of the infusions are available. There are several pain pump catheter kits available on the market including Stryker PainPump 2 (Stryker Corporation, USA), Accufuser disposable silicone balloon infuser (CME McKinley UK) and On-Q PainBuster (I-Flow Corporation, USA) (Figure 1). These pain pump catheters can be placed subcutaneously, suprafascially or subfascially (1). Patients find that these pumps are simple to use and are not cumbersome (11). Continuous bupivacaine in the immediate postoperative period may also play a preventive role in long-term chronic pain syndromes (19).

\section{THE EFFICACY OF PAIN PUMPS}

With the use of continuous local anesthetic infusions for postoperative analgesia across several surgical specialties, the efficacy of pain pumps on a large study population needs to be evaluated. In 2006, Liu et al (1) performed a meta-analysis on the available randomized controlled trials (RCTs). Forty-four prospective 


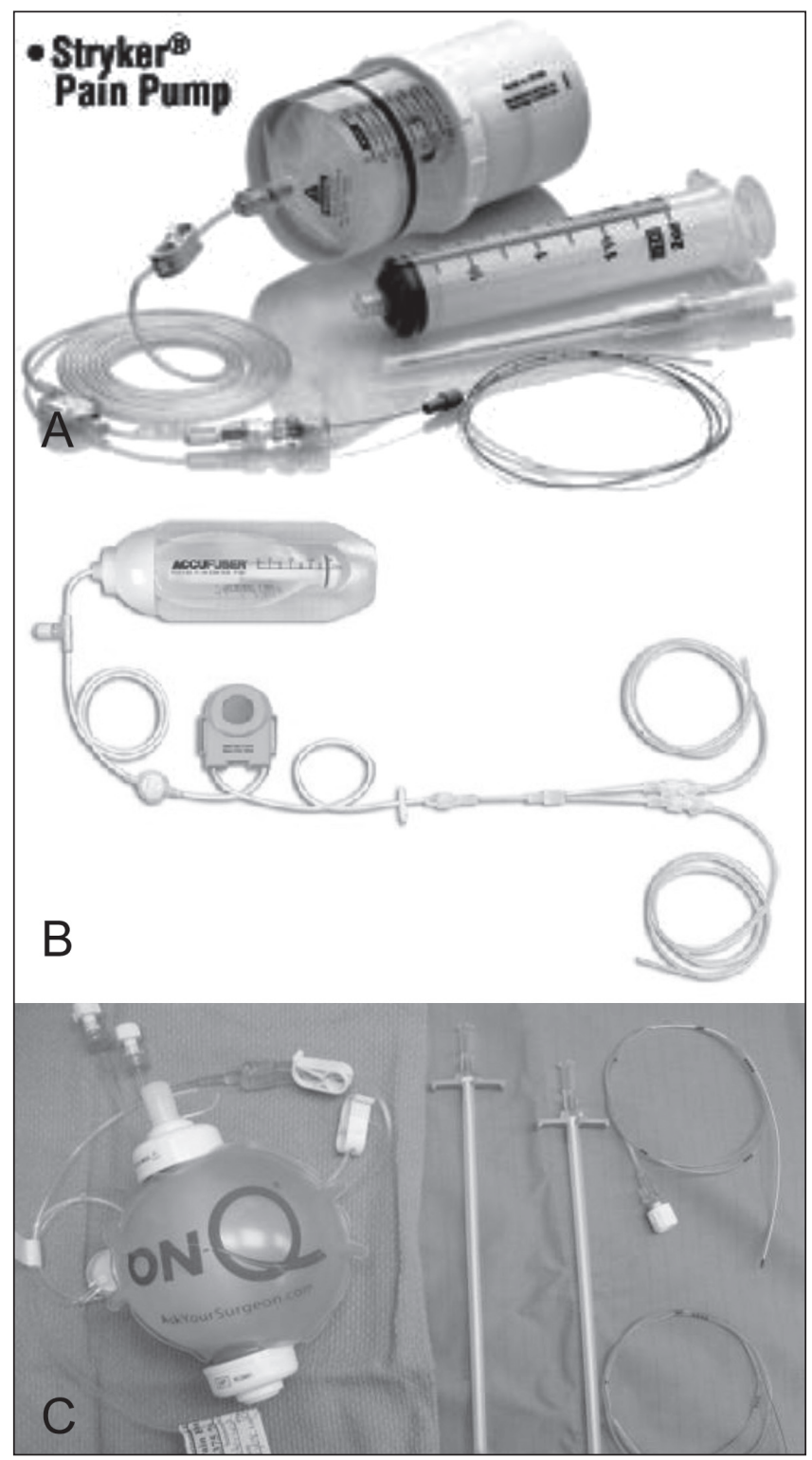

Figure 1) Types of local anesthetic infusion delivery systems. A Stryker PainPump 2 (Stryker Corporation, USA). B Accufuser disposable silicone balloon infuser (CME McKinley UK). C On-Q PainBuster (I-Flow Corporation, USA)

randomized trials met the inclusion criteria for analysis. Between 1983 and 2006, 2141 patients were studied in the trials that investigated continuous local anesthetic delivery in postsurgical wounds. The overall results were analyzed as well as the subgroups (by specialty). Cardiothoracic surgery (14 RCTs), orthopedic surgery (12 RCTs), general surgery (11 RCTs) and gynecology/urology (seven RCTs) were analyzed. At the time, there were no RCTs in the plastic surgery specialty that met the inclusion criteria. Despite the heterogeneity of the operative procedures, overall results and all subgroup analysis showed that continuous local anesthetic infusion improved pain scores and decreased the need for supplemental narcotics. These results were statistically significant.

Liu et al (1) reported that individual studies were infrequent in assessing PONV, side effects, length of hospital stay and satisfaction. However, an overall analysis of the patients did show that there was a statistically significant reduction in
PONV, length of hospital stay and increased patient satisfaction with the use of continuous infusions of local anesthetics. Furthermore, the overall local anesthetic toxicity was $0 \%$ and catheter failure due to technical problems was $1 \%$. The catheter-related infection rate ranged from $0.7 \%$ to $1.2 \%$ (1). Pain pumps have not been shown to be efficacious in all surgical procedures. Banerjee et al (20) and Webb et al (21) did not see any difference in pain scores using pain pumps in arthroscopic shoulder surgery. The pain pumps were not effective in iliac crest bone grafting (22) or radical retropubic prostatectomies (23). Cottam et al (24) showed that there was no difference in postoperative analgesic control after laparoscopic Roux-en-Y gastric bypass surgery between pain pumps and patient-controlled analgesia (PCA). However, there was a significant reduction in opioid use and PONV.

\section{PAIN PUMPS IN BREAST SURGERY}

Although pain pumps have been used in many surgical specialties for several years, their prevalence is relatively recent in plastic surgery procedures. One of the earliest published studies was by Pacik et al (25), in which 200 consecutive augmentation mammaplasty patients with bolus injections of bupivacaine via catheters were studied. The study found that patients were more comfortable and used less narcotics. Baroody et al (5), in a study of 16 prospective, immediate, autologous latissimus dorsi breast reconstruction with historical controls, showed that continuous infusion of bupivacaine decreased pain and narcotic use significantly in the postoperative period. They also observed that there was a reduction in PONV.

In 2005, Lu and Fine (26) published a prospective casecontrol study of two groups of 74 patients. Breast reduction and implant breast reconstruction patients were studied. Continuous bupivacaine infusion was administered to each group of patients, and each group was compared with patients receiving conventional analgesia. The breast reduction patients with continuous analgesia had statistically significant improvement in pain scores, narcotic analgesia use and length of hospital stay. There was no difference in complications or PONV. In the implant reconstruction group, there was significantly improved pain scores and less narcotic use in the study group. There was no statistical difference in PONV, length of hospital stay or complications. There were no implant infections in the study.

Losken et al (27) performed a case-control study on 32 transverse rectus abdominis myocutaneous flap breast reconstruction patients. They administered continuous bupivacaine into the abdominal incision for $48 \mathrm{~h}$ in 16 patients. There was a reduction in the requirement for narcotics as well as a shorter length of hospital stay for the pain pump group. However, the results were not statistically significant. None of the aforementioned studies had any complications or toxicities related to the local anesthetic.

\section{PROSPECTIVE RCTS IN BREAST SURGERY}

Kryger et al (28) investigated a group of 98 reduction mammaplasty patients in a prospective manner. The group had bilateral, inferior pedicle, Wise pattern reduction mammaplasties. Thirtyseven patients had pain pump placements and 61 patients had no pumps. The patients with the pain pumps had significantly less pain immediately on postoperative days 1 and 2 . They also had significantly less narcotic use, PONV and antiemetic use. 
Patients had a satisfaction rate of $97.3 \%$, and they preferred the self-administered bolus function for breakthrough analgesia. There were no complications related to the local anesthetic infusion or the pain pump itself.

Following up on the study, the same group of investigators published a double-blinded, prospective, RCT in 2008 (29). Patients with inferior pedicle, Wise pattern bilateral reduction mammaplasties were studied. Thirty-one patients were enrolled in the study. Continuous infusion of $0.25 \%$ bupivacaine was used in the study group for two days. The study group had statistically significant improved pain scores immediately on postoperative days 1 and 2 when compared with the control group, who received continuous saline infusions. The study group also had reduced opiate use, decreased PONV and decreased antiemetic use. There were two technical pain pump complications but no infections or local anesthetic toxicity. There was a 93\% overall patient satisfaction with the pain pumps, which was statistically significantly greater than the saline group satisfaction rate.

In 2008, Kazmier et al (30) published an interesting study that investigated the use of pain pumps in bilateral augmentation mammaplasty patients. It was a prospective RCT of 20 patients. Individual patients were randomly assigned according to which breast received the local anesthetic; thus, each patient served as an internal control. The results revealed that there was no statistically significant difference in pain scores. However, the number of patients in each group was small. Nevertheless, the study did raise concerns that local anesthetic infusion via pain pumps in augmentation mammaplasty patients may not be effective compared with placebo.

A prospective, double-blind RCT of the use of pain pumps in muscle-sparing transverse rectus abdominis myocutaneous flaps was investigated by Heller et al (31). The study included 48 randomly assigned patients who received bupivacaine or saline via the pain pump above and below the rectus abdominis fascia, as well as PCA and oral narcotics, postoperatively. There was significant improvement in patient satisfaction in the bupivacaine group, and their PCA narcotic use was decreased in the first $48 \mathrm{~h}$. However, the abdominal pain intensity scores and the total narcotic use for the entire length of hospital stay were not statistically different between the two groups.

\section{PAIN PUMPS IN OTHER PLASTIC SURGERY PROCEDURES}

In 2007, Bray et al (32) published a retrospective study that investigated the use of bupivacaine infusion in abdominoplasty. In 38 patients, they found no statistical difference in pain scores, antiemetic use or hospital stay. Mentz et al (33) placed pain pumps in 10 abdominoplasty patients and found that they had better analgesia than the controls. These patients also ambulated earlier. In 2003, Kulkarni and Elliot (34) reported a prospective cohort of hand surgery patients who were treated with pain pumps. There was 'adequate' treatment of pain with a pain pump in $91 \%$ of patients. However, the pain was not completely blocked in these patients. They also reported two cases of infection of the cannula that delivered the local anesthetic.

There are no reported studies of the use of pain pumps in head and neck reconstruction, facial aesthetic surgery, or upper or lower extremity reconstruction. There is a paucity of literature on the ideal placement of the pain pumps. No conclusive evidence is present regarding whether surgical drains interfere with the efficacy of pain pumps. Also, the surgeon must be aware of the cardiac and neurological sequelae of bupivacaine toxicity. Care must be taken to not exceed the daily maximum bupivacaine dose of $400 \mathrm{mg}$, including the amount infiltrated with surgery as well as the total amount infused via the pain pump.

\section{CONCLUSION}

The use of continuous infusions of local anesthetic for postoperative analgesia has been widely used and extensively studied in many of the surgical specialties. Across a wide variety of procedures, these infusions have been shown to decrease, but not eliminate, pain. They have also been shown to decrease narcotic use postoperatively, decrease PONV, improve patient satisfaction and, perhaps, decrease hospital length of stay. These pain pumps have been increasingly gaining widespread use in plastic surgery with similar results in other surgical specialties. They have a low incidence of complications and low systemic toxicity. Even though they are popular, the cost-effectiveness of these pain pumps needs further investigation. Their efficacy in head and neck reconstruction, facial aesthetic surgery, hand surgery, lower extremity reconstruction and other areas of plastic surgery need further study with well-designed, prospective RCTs. Currently, pain pumps reduce pain but do not eliminate it. In the future, pain pumps may be used in innovative ways to completely eradicate postoperative pain if plastic surgeons are able to create a way to deliver the local anesthetics to all the nerves supplying the surgical field.

DISCLOSURE: The present study was not funded by any individual, institution or agency. The authors have no financial interests in any of the products referenced in the present review. None of the authors have consultancies, stock ownership or other equity interests, or patent licensing arrangements with any of the products or companies that own the products mentioned in the present review. Dr Lalonde is a consultant for Accurate Surgical \& Scientific Instruments Corporation (USA).

\section{REFERENCES}

1. Liu SS, Richman JM, Thirlby RC, Wu CL. Efficacy of continuous wound catheters delivering local anesthetic for postoperative analgesia: A quantitative and qualitative review of randomized controlled trials. J Am Coll Surg 2006;203:914-32.

2. Pu LLQ. The use of a pain pump for optimal postoperative pain management. Plast Reconstr Surg 2006;117:2066-9.

3. Chester JF, Ravindranath K, White BD, Shanahan D, Taylor RS, Lloyd-Williams K. Wound perfusion with bupivacaine: Objective evidence for efficacy in post-operative pain relief. Ann R Coll Surg Engl 1989;71:394-6.

4. Enneking FK, Ilfeld BM. Major surgery in the ambulatory environment; continuous catheters and home infusions. Best Pract Res Clin Anaesthesiol 2002;16:285-94.

5. Baroody M, Tameo M, Dabb RW. Efficacy of the PainPump catheter in immediate autologous breast reconstruction. Plast Reconstr Surg 2004;114:895-99.

6. Gibson MP, Vetter T, Crow JP. Use of continuous retropleural bupivacaine in postoperative pain management for pediatric thoracotomy. J Ped Surg 1999;34:199-201.

7. Barron DJ, Tolan MJ, Lea RE. A randomized control trial of continuous extra-pleural analgesia post-thoracotomy: Efficacy and choice of local anesthetic. Eur J Anaesthesiol 1999;16:236-45.

8. Zohar E, Fredman F, Phillopov A, Jedeikin R, Shapiro A. The analgesic efficacy of patient-controlled bupivacaine wound 
instillation after total abdominal hysterectomy with bilateral salpingo-oophorectomy. Anesth Analg 2001;93:482-7.

9. Ilfeld BM, Gearen PF, Enneking FK, et al. Total knee arthroplasty as an overnight-stay procedure using continuous femoral nerve blocks at home: A prospective feasibility study. Anesth Analg 2006;102:87-90.

10. Cheong WK, Seow-Choen F, Eu KW, Tang CI, Heah SM. Randomized clinical trial of local bupivacaine perfusion versus parenteral morphine infusion for pain relief after laparotomy. Br J Surg 2001;88:357-9.

11. Fredman B, Shapiro A, Zohar E. The analgesic efficacy of patient controlled ropivacaine instillation after cesarean delivery. Anaesth Anal 2000;91:1436-40.

12. Sherwinter DA, Ghaznavi AM, Spinner D, Savel RH, Macura JM, Adler H. Continuous infusion of intraperitoneal bupivacaine after laparoscopic surgery: A randomized controlled trial. Obes Surg 2008;18:1581-6.

13. Grant AJ, Wood C. The effect of intraneural local anesthetic infusion on pain following major lower limb amputation. Scott Med J 2008;53:4-6.

14. Magnani E, Corosu R, Mancino P, Borgia ML. Postoperative analgesia after cesarean section by continued administration of levobupivacaine with the On-Q Painbuster system over the fascia vs ketorolac + morphine i.v. Clin Exp Obstet Gynecol 2006;33:223-5.

15. Schell SR. Patient outcomes after axillary lymph node dissection for breast cancer: Use of postoperative continuous local anesthetic infusion. J Surg Res 2006;134:124-32.

16. Wheatley GH, Rosenbaum DH, Paul MC, et al. Improved pain management outcomes with continuous infusion of local anesthetic after thoracotomy. J Thorac Cardiovasc Surg 2005;130:464-8.

17. LeBlanc KA, Bellanger D, Rhynes VK, Hausmann M. Evaluation of continuous infusion of $0.5 \%$ bupivacaine by elastomer pump for postoperative pain management after open inguinal hernia repair. J Am Coll Surg 2005;200:198-202.

18. Schurr MJ, Gordon DB, Pellino TA, Scanlon TA. Continuous local anesthetic infusion for pain management after outpatient inguinal herniorrhaphy. Surgery 2004;136:761-9.

19. Katz J, Jackson M, Kavanagh BP, Sandler AN. Acute pain after thoracic surgery predicts long-term post-thoracotomy pain. Clin J Pain 1996;12:50-5.

20. Banerjee SS, Pulido P, Adelson WS, Fronek J, Hoenecke HR. The efficacy of continuous bupivacaine infiltration following arthroscopic rotator cuff repair. Arthroscopy 2008;24:397-402.

21. Webb D, Guttman D, Cawley P, Lubowitz JH. Continuous infusion of a local anesthetic versus interscalene block for postoperative pain control after arthroscopic surgery. Arthroscopy 2007;23:1006-11.
22. Morgan SJ, Jeray KJ, Saliman LH, et al. Continuous infusion of local anesthetic at iliac crest bone graft sites for post operative pain relief: A randomized double-blind study. J Bone Joint Surg Am 2006;88:2606-12

23. Wu CL, Partin AW, Rowbingson AJ, Kalish MA, Walsh PC, Fleischer LA. Efficacy of continuous local anesthetic infusion for postoperative pain after radical retropubic prostatectomy. Urology 2005;66:366-70.

24. Cottam DR, Fisher B, Atkinson J, et al. A randomized trial of bupivacaine pain pumps to eliminate the need for PCA pumps in primary laparoscopic Roux-en-Y gastric bypass. Obes Surg 2007:17:595-600

25. Pacik PT, Werner C, Jackson N, Lobsitz C. Pain control in augmentation mammaplasty: The use of indwelling catheters in 200 consecutive patients. Plast Reconstr Surg 2003;111:2090-6.

26. Lu L, Fine NA. The efficacy of continuous local anesthetic infiltration in breast surgery: Reduction mammaplasty and reconstruction. Plast Reconstr Surg 2005;115:1927-34.

27. Losken A, Parris JJ, Douglas TD, Codner MA. Use of the infusion pain pump following transverse rectus abdominis muscle flap breast reconstruction. Ann Plast Surg 2005;54:479-82.

28. Kryger ZB, Rawlani V, Lu L, Fine NA. Decrease post-operative pain, narcotic and antiemetic use after breast reduction using a local anesthetic pain pump. Ann Plast Surg 2008;61:147-52

29. Rawlani V, Kryger ZB, Lu L, Fine NA. A local anesthetic pump reduces pain and narcotic and antiemetic use in breast reconstruction surgery: A randomized controlled trial. Plast Reconstr Surg 2008;122:39-52.

30. Kazmier FR, Henry SL, Christiansen D, Puckett CL. A prospective, randomized, double-blind, controlled trial of continuous local anesthetic infusion in cosmetic breast augmentation. Plast Reconstr Surg 2008;121:711-5.

31. Heller L, Kowalski AM, Wei C, Butler CE. Prospective, randomized, double-blind trial of local anesthetic infusion and intravenous narcotic patient-controlled anesthesia pump for pain management after free TRAM flap breast reconstruction. Plast Reconstr Surg 2008;122:1010-8.

32. Bray DA, Nguyen J, Craig J, Cohen BE, Collins DR. Efficacy of a local anesthetic pump in abdominoplasty. Plast Reconstr Surg 2007;119:1054-9.

33. Mentz HA, Ruiz-Razura A, Newall G, Patronella CK. Use of a regional infusion pump to control postoperative pain after an abdominoplasty. Aesth Plast Surg 2005;29:415-21.

34. Kulkarni M, Elliot D. Local anaesthetic infusion for postoperative pain. J Hand Surg 2003;28:300-6. 